\title{
Ethyl acetate extract of Wedelia chinensis inhibits tert-butyl hydroperoxide-induced damage in PC12 cells and D-galactose-induced neuronal cell loss in mice
}

Wea-Lung Lin ${ }^{1,2}$, Shao-Ming Wang ${ }^{3}$, Ying-Jui Ho ${ }^{4}$, Hsing-Chun Kuo ${ }^{5}$, Yean-Jang Lee ${ }^{6}$ and Tsui-Hwa Tseng ${ }^{3,7^{*}}$

\begin{abstract}
Background: Wedelia chinensis is traditionally used as a hepatoprotective herb in Taiwan. The aim of this study was to evaluate the neuroprotective potential of $W$. chinensis.

Methods: An ethyl acetate extract of W. chinensis (EAW) was prepared and analyzed by HPLC. The neuroprotective potential of EAW was assessed by tert-butylhydroperoxide (t-BHP)-induced damage in PC12 cells and D-galactoseinduced damage in mouse cortex.

Results: EAW exhibited potent radical scavenging property and highly contained luteolin and wedelolactone. EAW decreased t-BHP-induced reactive oxygen species (ROS) accumulation, cytotoxicity and apoptosis in PC12 cells. EAW and its major constituents blocked t-BHP-induced cytochrome $\mathrm{C}$ release and $\mathrm{Bcl}-2$ family protein ratio change. EAW and its major constituents increased the endogenous antioxidant capacity evaluated by the binding activity assay of nuclear factor E2-related factor 2 (Nrf2) to antioxidant response element (ARE) and nuclear translocation of Nrf2 respectively in PC12 cells. Finally, EAW inhibited D-galactose-induced lipid peroxidation, apoptosis and neuron loss in the cerebral cortex of mice.
\end{abstract}

Conclusion: These results demonstrate that $W$. chinensis has neuroprotective potential through blocking oxidative stress-induced damage and that luteolin and wedelolactone contribute to the protective action.

Keywords: Apoptosis, t-butylhydroperoxide, D-galactose, Luteolin, Wedelia chinensis, Wedelolactone

\section{Background}

Oxidative tress occurs when the production of reactive oxygen species (ROS) or their products are in excess of antioxidant defense mechanism. The brain is especially vulnerable to oxidative stress compared to other organs because it exhibits lower antioxidant enzyme activity and contains an abundance of unsaturated fatty acids, which are the targets of lipid peroxidation. Thereafter oxidative stress contributes to the neurodegenerative disorders, and is one of the earliest pathological changes in Alzheimer's disease [1]. Apart from quenching free radicals, antioxidants may

\footnotetext{
*Correspondence: tht@csmu.edu.tw

${ }^{3}$ School of Medical Applied Chemistry, Chung Shan Medical University, No. 110, Section 1, Chien-Kuo N. Road, Taichung 402, Taiwan

${ }^{7}$ Department of Medical Education, Chung Shan Medical University Hospital, No. 110, Section 1, Chien-Kuo N. Road, Taichung 402, Taiwan

Full list of author information is available at the end of the article
}

combat the ROS generation and block ROS-mediated deleterious effects by gene regulation. Supplementations with exogenous antioxidants from diets as well as medicinal herbs catch attention on avoid unwanted neuropathophysiology.

Tertiary butyl hydroperoxide (t-BHP), a simple lipophilic alkyl hydroperoxide, has been reported to induce dosedependent oxidative stress and damage in brain cells [2]. The alkoxyl and alkyl radicals derived from $\mathrm{t}$-BHP are a species that produce cell damage $[3,4]$. Furthermore, t-BHP-induces a cellular redox imbalance may induce cell apoptosis [5]. Therefore, t-BHP is a useful inducer for investigating the effectiveness of various neuroprotection products against oxidative stress. In addition, D-galactose at normal concentrations can be metabolized by D-galactokinase and galactose-1-phosphate 
uridyltransferase. However, high concentrations are converted into aldose and hydroperoxide by galactose oxidase, resulting in the generation of ROS in the brain [6,7], which can affect bimolecules including protein, DNA and lipids and which may lead to consecutive functional disturbance and cell death. Thus, treatment of animals with D-galactose may serve as a useful model for studying the effect of neuroprotective agents.

Wedelia chinensis, a Wedelia genus plant belonging to the Compositae, has been traditionally used as a hepatoprotective tea material in Taiwan [8]. W. chinensis possesses multiple activities such as anti-microbial, antiinflammatory, anti-cancer, and CNS-depressant activity [9-11]. Previously, Lin reported that W. chinensis contained four compounds capable of suppressing androgen activity: luteolin, apigenin, indole-3-carboxyaldehyde and wedelolactone [12]. Luteolin and apigenin, belonging to flavonoid structure, have been reported to reveal antioxidant, anti-inflammatory, and anti-cancer effects [13-15]. Wedelolactone, belonging to coumarin structure, has been demonstrated to exhibit a wide range of biological effects including anti-inflammation, immunomodulatory, antimyotoxic, anti-oxidant, anti-phlogistic, anti-haemorrhagic, anti-hepatotoxic and anti-cancer activity [16-20]. Since the neuroprotection potential of $W$. chinensis is not well understood, in the present study we used two models, in vitro and in vivo, to evaluate its neuroprotective potential.

\section{Methods}

\section{Reagents and materials}

Dulbecco's modified Eagle's medium (DMEM), fetal bovine serum, and penicillin/streptomycin were purchased from GIBCO Ltd. (Grand Island, NY, USA). Antibodies, such as anti-Bcl-2, $-\mathrm{Bcl}-\mathrm{X}_{\mathrm{L}},-\mathrm{Bax},-\mathrm{Nrf} 2$ and $-\beta$-actin antibodies were obtained from Santa Cruz Biotechnology (Santa Cruz, CA). The herb, W. chinensis, was purchased from a reputable folk medicine store in Taiwan and identified by associate professor Ko-Kaung Liao, who majors in Biology and is familiar with medicinal plants. Wedelolactone, 7-methoxy-5, 11, 12-trihydroxy-coumestan, was synthesized from commercially available phloroglucinol [21]. All chemicals were analytical grade purchased from Sigma-Aldrich (USA) and Merck (Germany).

\section{Preparation of the crude extract}

The air-dried whole plant of $W$. chinensis was shredded in a blender and extracted with 5 volumes of $95 \%$ ethanol at room temperature for 2 days. The mixture was filtered through filter paper $(5 \mu \mathrm{m}$ pore size), and the filtrate was dried using rotary evaporation under vacuum at $40^{\circ} \mathrm{C}$. The percentage yield was $9.3 \%(\mathrm{w} / \mathrm{w})$. The crude ethanolic extract was suspended in distilled water and partitioned successively with n-hexane and ethyl acetate, respectively to obtained semi-crudes. All dried extracts, including ethanol extract, n-hexane extract (HEW), and ethyl acetate extract (EAW) were stored at $-20^{\circ} \mathrm{C}$ prior to use in the following studies.

\section{DPPH radical scavenging assay}

The 2,2-diphenyl-1-picrylhydrazyl (DPPH) method measures the reaction of the antioxidants with the stable DPPH radical in a methanol solution. Briefly, a $60 \mu \mathrm{M}$ DPPH radical solution was freshly made in methanol. Various concentrations of the sample extracts were reacted with the DPPH radical solution $(3 \mathrm{~mL})$ for $45 \mathrm{~min}$ at room temperature, and the absorbance was measured at $517 \mathrm{~nm}$. The affinity of the test material to quench the DPPH free radical was evaluated according to the equation scavenging $\%=$ (absorbance of control group-absorbance of the extract added group)/absorbance of control group $\times 100 \%$.

\section{HPLC analysis}

EAW was analyzed using a Hitachi L7100 HPLC system with a $5-\mu \mathrm{m}$ ODS-Hypersil column $(250 \times 4.6 \mathrm{~mm})$. The mobile phase was generated from solvent A [acetonitrile: $\mathrm{H}_{2} \mathrm{O}$ : acetic acid (90:10:3)] and solvent B [acetonitrile: $\mathrm{H}_{2} \mathrm{O}$ : acetic acid (10:90:3)] using the following gradient program: $0-3 \mathrm{~min} 100 \%$ solvent B, 3-8 min $85 \%$ solvent B, 8-15 min $80 \%$ solvent B, $15-40$ min $60 \%$ solvent B. The detection wavelength was $360 \mathrm{~nm}$, and the flow rate $0.8 \mathrm{~mL} / \mathrm{min}$. Quantization was carried out by the external standard method on the basis of the area at $360 \mathrm{~nm}$ using calibration curve of wedelolactone and luteolin.

\section{Cell culture}

Adrenal pheochromocytoma (PC12) cells were maintained in DMEM medium containing 5\% fetal bovine serum, $10 \%$ horse serum, and $100 \mathrm{U} / \mathrm{mL}$ penicillin and streptomycin in a $5 \% \mathrm{CO}_{2}$ incubator at $37^{\circ} \mathrm{C}$.

\section{Preparation of nuclear protein and analysis of antioxidant-response element (ARE) binding activity of nuclear factor E2-related factor 2(Nrf2)}

PC12 cells $\left(1 \times 10^{6}\right.$ cells $\left./ \mathrm{ml}\right)$ were exposed to the indicated reagent or vehicle (0.1\% DMSO) for 6 h. Nuclear extracts were harvested using NE-PER nuclear extraction reagent (Thermo Fisher Scientific, Rockford, IL, USA) according to the manufacture's instructions. Nuclear protein concentrations were determined using the Bio-Rad protein assay reagent. The amount of Nrf2 available in the nucleus to bind AREs was determined using a TransAM Nrf2 Transcription Factor ELISA Kit (Active Motif Inc., Carlsbad, CA, USA) according to the manufacturer's instructions. Briefly, nuclear extracts $(2.5 \mu \mathrm{g})$ were added to wells that contained the immobilized consensus ARE oligonucleotide. A primary anti-Nrf2 
antibody was added to each well, followed by a horseradish peroxidase-conjugated secondary antibody. The signal was detected at $450 \mathrm{~nm}$, and Nrf/ARE binding activity is reported as $\mathrm{A}_{450}$.

\section{Intracellular ROS analysis}

PC12 cells were pretreated with EAW for $24 \mathrm{~h}$ and then treated with or without $100 \mu \mathrm{M}$ of $\mathrm{t}$-BHP for $3 \mathrm{~h}$. After the indicated treatments, PC12 cells were incubated with the fluorescent probe $2^{\prime}, 7^{\prime}$-dichlorofouorescein diacetate (DCFH-DA; $10 \mu \mathrm{M}$ ) for $30 \mathrm{~min}$. DCFH-DA becomes highly fluorescent $2^{\prime}, 7^{\prime}$-dichlorofouorescein (DCF) upon oxidation by ROS, and then washed twice with PBS. Finally the fluorescence intensity of DCF was measured in a microplate reader with an excitation wavelength $485 \mathrm{~nm}$ and an emission wavelength of $535 \mathrm{~nm}$.

\section{Determination of cytotoxicity by LDH release assays}

Cells were seeded in 24-well plates at a density of $2 \times 10^{5}$ cells/ml. PC12 cells were pretreated with EAW (0, 10, 25 and $50 \mu \mathrm{g} / \mathrm{mL}$ ) for $24 \mathrm{~h}$ and then treated with or without $100 \mu \mathrm{M}$ of $\mathrm{t}-\mathrm{BHP}$ for $3 \mathrm{~h}$. The cytotoxicity was quantitatively assessed by measuring the activity of the lactate dehydrogenase $(\mathrm{LDH})$ released from the damaged cells into the culture medium. At the end of the treatment, the media was used for the LDH activity assay. The enzyme was determined by using an assay kit according to the manufacturer's protocol. The absorbance of the samples was read at $490 \mathrm{~nm}$ using a microplate reader. The LDH release was proportional to the number of damaged $\mathrm{PC} 12$ cells.

\section{Sub- $\mathrm{G}_{0} / \mathrm{G}_{1}$ hypodiploid FACS analysis}

After treatment, the cells were fixed with ice-cold $70 \%$ ethanol overnight. The cells were then centrifuged at $1500 \mathrm{~g}$ for $10 \mathrm{~min}$ and resuspended in PBS containing $0.5 \%$ Triton X-100, $0.1 \mathrm{mg} / \mathrm{mL}$ RNase, and $40 \mu \mathrm{g} / \mathrm{mL}$ propidium iodide (PI) at room temperature for $30 \mathrm{~min}$. Cellular DNA content (10,000 cells per analysis) was determined by flow cytometric analysis of PI-labeled cells using a FACSCalibur flow cytometer (Becton Dickinson, San Jose, CA) equipped with a single argon-ion laser $(488 \mathrm{~nm})$. Cell cycle was analyzed using Modfit software (Verity Software House, Topsham, ME) and those cells in apoptosis were indicated by the substantially lower DNA content compared to the $G_{0} / G_{1}$ peak in the DNA histogram.

\section{Western blotting analysis}

The cells were washed in PBS with $1 \mathrm{mM}$ zinc ion and lysed in radioimmunoprecipitation assay (RIPA) buffer (50 mM Tris-buffer, $5 \mathrm{mM}$ EDTA, $150 \mathrm{mM} \mathrm{NaCl}, 1 \%$ NP 40, 0.5\% deoxycholic acid, $1 \mathrm{mM}$ sodium orthovanadate, $81 \mu \mathrm{g} / \mathrm{mL}$ aprotinin, $170 \mu \mathrm{g} / \mathrm{mL}$ leupeptin, and
$100 \mu \mathrm{g} / \mathrm{mL}$ PMSF; pH 7.5). The mixtures were mixed for $30 \mathrm{~min}$ at $4^{\circ} \mathrm{C}$ and centrifuged $(10,000 \mathrm{~g})$ for $10 \mathrm{~min}$. The supernatants were collected as whole-cell extracts. The protein content was determined with the Bio-Rad protein assay reagent using bovine serum albumin as a standard. Protein samples (50 to $100 \mu \mathrm{g}$ protein) were boiled, separated on an SDS polyacrylamide gel, electrophoretically transferred to nitrocellulose membranes (Amersham, Arlington Heights, IL) and blotted with the indicated primary antibodies. The proteins were visualized with horseradish peroxidase (HRP)-conjugated secondary antibodies (Zymed Laboratory, Inc., San Francisco, CA) followed by chemiluminescence (ECL-Plus; Santa Cruz Biotechnology). The relative photographic density was quantified using densitometry.

\section{Assessment of cytochrome $\mathrm{C}$ release}

Cells were harvested and washed with ice-cold PBS at the end of treatment to prepare the cytosolic fraction. The cell pellet was resuspended in $500 \mu \mathrm{L}$ buffer A $(20 \mathrm{mM}$ HEPES-KOH, pH 7.5, $10 \mathrm{mM} \mathrm{KCl,} 1.5 \mathrm{mM} \mathrm{MgCl}, 1 \mathrm{mM}$ sodium EDTA, $1 \mathrm{mM}$ leupeptin and $1 \mu \mathrm{g} / \mathrm{mL}$ chymostatin) and homogenized using a Pyrex glass homogenizer and a type $\mathrm{B}$ pestle (40 strokes). The homogenate was centrifuged at $100,000 \mathrm{~g}\left(4^{\circ} \mathrm{C}\right.$ for $\left.1 \mathrm{~h}\right)$ to generate the cytosolic fraction. A Bio-Rad protein assay kit determined protein concentrations, and $25 \mu \mathrm{g}$ of each fraction was separated using $15 \%$ SDS-PAGE. The proteins were transferred to an NC membrane, and then reacted sequentially with a primary antibody (anti-cytochrome $\mathrm{C}$ and anti- $\beta$-actin as internal controls) and a secondary peroxidase-conjugated antibody. Protein bands were revealed using enhanced chemiluminescence (ECL commercial kit).

\section{Animals and treatments}

Five-week-old male ICR mice were purchased from GlycoNex Inc. (Taiwan) and kept in groups of three to four per cage in an animal room at a temperature of $22 \pm 2{ }^{\circ} \mathrm{C}$, $12 \mathrm{~h}$ light-dark cycle, and relative humidity $50-70 \%$. The mice were provided with rodent chow and water ad libitum. All experiments were approved by the Animal Care Committee of Chung Shan Medical University (IACUC approval No. 896). After adaptation for a week, the mice were randomly divided into 4 groups $(n=6)$. Group 1 served as the vehicle control and received daily subcutaneous (s.c.) injections of $0.1 \mathrm{~mL}$ of distilled water and three intraperitoneal (i.p.) injections/week of $1 \%$ DMSO in distilled water for 9 weeks. Group 2 received daily s.c. injections of $50 \mathrm{mg} / \mathrm{kg}$ of D-galactose in distilled water and three i.p. injections/week of $0.1 \mathrm{~mL}$ of $1 \%$ DMSO in distilled water for 9 weeks. Groups 3 and group 4 received the same s.c. injections of D-galactose plus three i.p. injections/week of $0.1 \mathrm{~mL}$ of $1 \%$ DMSO containing, respectively, $10 \mathrm{mg} / \mathrm{kg}$ or $25 \mathrm{mg} / \mathrm{kg}$ of EAW. 


\section{Preparation of brain samples and measurement of lipid peroxidation}

Mice were euthanized and the brain removed and dissected on an ice-bath plate. The right cerebral cortex was fixed in $10 \%$ paraformaldehyde for histological studies and the left cerebral cortex was homogenized in 10 volumes $(\mathrm{v} / \mathrm{w})$ of ice-cold saline containing a protease inhibitor cocktail (Sigma-Aldrich, MO, USA). The resultant homogenate was centrifuged and the supernatant was removed for lipid peroxidation determination. The amount of malondialdehyde (MDA) was measured by reaction with thiobarbituric acid and the absorbance read at $532 \mathrm{~nm}$ on a spectrophotometer.

\section{TUNEL staining and histopathological examination}

The cerebral cortex samples were dehydrated, embedded in paraffin blocks after post-fixation, then sliced and the sections stained with terminal deoxynucleotidyl transferase dUTP nick end labeling (TUNEL). The TUNEL positive cells were visualized using the peroxidase-DAB reaction and counterstained with hematoxylin. Detailed procedures followed the manufacturer's protocol for the in situ Apoptosis Detection Kit (In Situ Cell Death Detection Kit; Roche Diagnostics, Mannheim, Germany) according to the manufacturer's instructions. The digital images were captured using a digital camera (Canon A640, Tokyo, Japan). Quantification of apoptotic cells was by measuring three randomly selected microscopic fields (100× magnification) for each slide. The percentage of TUNEL-positive cell $(\%)=100 \times$ (TUNEL-positive cells/total cells). In addition, the sections were stained with hematoxylin-eosin for light microscopic analysis. Large nuclei and dark staining neurons in the cerebral cortex were counted in five random fields per slide at $400 \times$ magnification and the density of neurons expressed as no. $/ \mathrm{mm}^{2}$.

\section{Statistical analysis}

Statistical significance was determined using one-way analysis of variance (ANOVA) followed by Dunnett's or Tukey's post hoc test. $P$ values less than 0.05 were considered statistically significant.

\section{Results and discussion}

Free radical scavenging activity and main constituent of EAW

Bleaching of DPPH was performed to determine the free radical scavenging capacity of the crude extracts. In our preliminary study, ethanol extract of $W$. chinensis exhibited free radical scavenging activity, and after solvent partition, it showed EAW increased the potency of free radical scavenging activity, with $10 \mu \mathrm{g} / \mathrm{mL}$ of EAW quenching $~ 50 \%$ of free radicals (Figure 1A). Then HPLC analysis examined the composition of EAW as compared with the authentic samples. This demonstrated that wedelolactone and luteolin were the main constituents (retention time $19.02 \mathrm{~min}$ and $28.15 \mathrm{~min}$ ) (Figure 1B). The content of wedelolatone in EAW was $12.8 \%$ and luteolin was $11.4 \%$ respectively.

\section{EAW activates nuclear Nrf2-ARE binding activity}

Figure 1 shows that EAW exhibited radical scavenging activity. In addition to direct scavenging radicals, whether noncytotoxic concentration of EAW has antioxidant enzyme induction activity in PC12 cells was investigated. The antioxidant response element (ARE) is a cis-acting enhancer sequence found in the promoter region of many genes encoding antioxidant enzymes/proteins. Nrf2 is a major ARE-binding transcription factor and induces the expression of antioxidant enzymes. Thereafter, whether EAW can enhance binding activity of nuclear Nrf2 to the ARE was evaluated. It was found that treatment with noncytotoxic concentration of EAW (25 and $50 \mu \mathrm{g} / \mathrm{mL}$ ) significantly activated Nrf2-binding activity (Figure 2).

\section{Effects of EAW on t-BHP-induced intracellular ROS, cytotoxicity and apoptosis}

The intracellular level of ROS with or without EAW treatment prior to $\mathrm{t}$-BHP exposure was evaluated. The treatment of PC12 cells with $100 \mu \mathrm{M}$ t-BHP for $3 \mathrm{~h}$ increased DCF fluorescence. It implicated t-BHP induced intracellular ROS. In our preliminary study, pretreatment of EAW for $6 \mathrm{~h}$ didn't exhibited apparent reduction effect on t-BHP-induced intracellular ROS (data not shown). However, pretreatment of EAW for $24 \mathrm{~h}$ showed reducing effect significantly (Figure 3). Thereafter, pretreatment of EAW for $24 \mathrm{~h}$ was used in the following cell culture study. $\mathrm{LDH}$ is a stable cytoplasmic enzyme that is present in all cells, including neurons. LDH is rapidly released into the cell culture medium when the cell plasma membrane is damaged. Therefore, $\mathrm{LDH}$ is a reliable biochemical index for neuronal cytotoxicity. Treatment with t-BHP for $3 \mathrm{~h}$ increased LDH release into the medium to $123.0 \pm 3.3 \%$ of control (Figure 4A). Pretreatment with different EAW concentrations prior to t-BHP exposure significantly inhibited $\mathrm{LDH}$ leakage in the PC12 cell system compared to t-BHP treated alone group (Figure 4A). The flow cytometry analysis was used to evaluate the $\mathrm{t}$-BHP-induced apoptosis of PC12 cells (Figure 4B). It showed t-BHP-induced 23.21\% sub- $G_{0} / G_{1}$ phase, which indicated DNA degradation and the cells undergoing apoptosis. With the pretreatment of 25 and $50 \mu \mathrm{g} / \mathrm{mL}$ EAW significantly declined to $16.83 \%$ and $11.30 \%$ respectively compared to $\mathrm{t}$-BHP treated alone group (Figure 4B).

Effects of EAW and its major constituents on t-BHPinduced changes in cytochrome $\mathrm{C}$ and the $\mathrm{Bcl}-2$ family Oxidative stress initiates mitochondrial apoptotic signals $[22,23]$. The loss of mitochondrial cytochrome $\mathrm{C}$ and its 

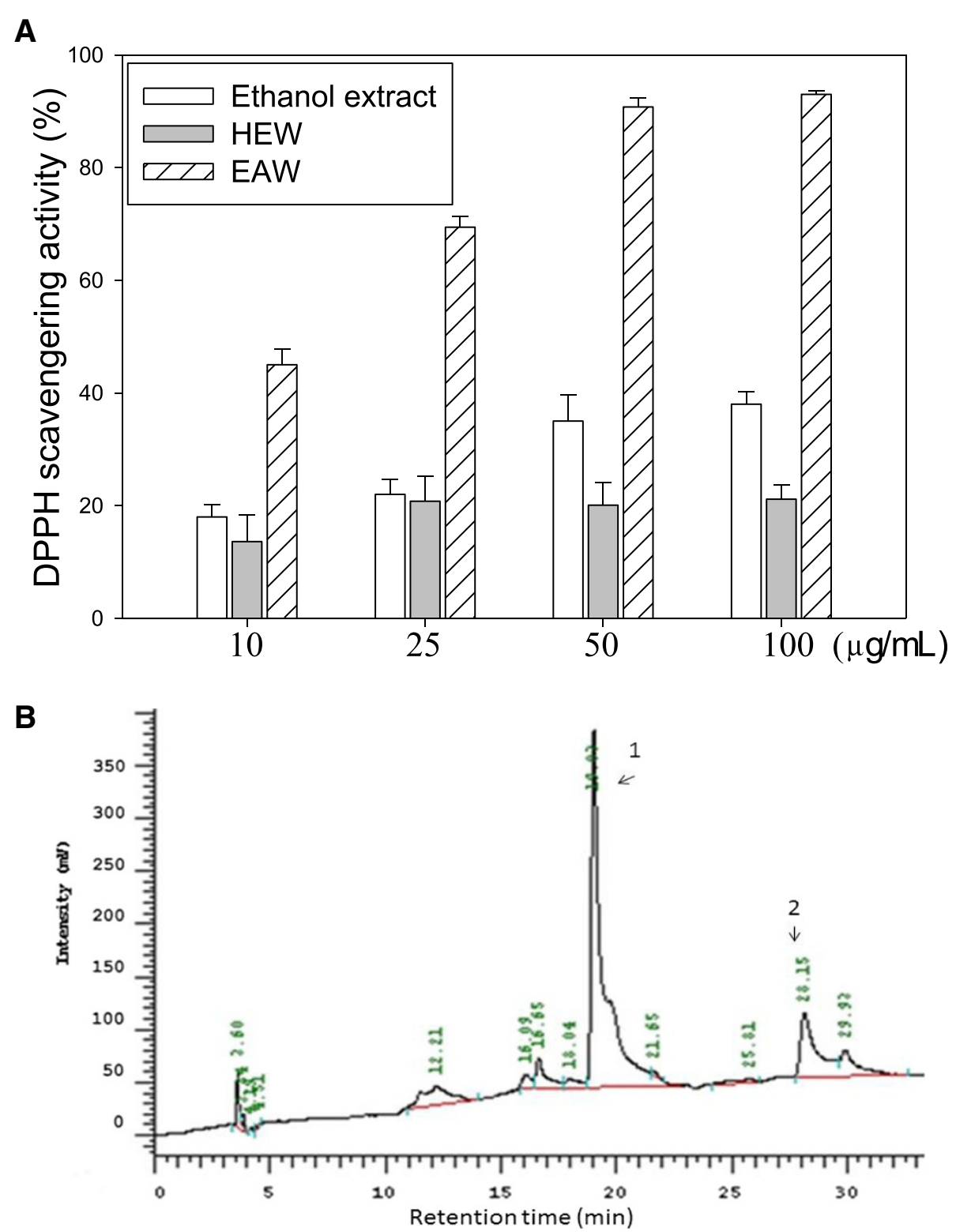

Figure 1 DPPH quenching effect and HPLC analysis of Wedelia chinesis extract. (A) The indicated concentrations of the ethanol extract, hexane extract (HEW), and ethyl acetate extract (EAW) of Wedelia chinensis were evaluated for DPPH quenching capacity as described in the text. $\%$ of DPPH scavengering activity = (absorbance of control group - absorbance of the extract added group)/absorbance of control group $\times 100 \%$. Means \pm SD $(n=3)$. (B) HPLC analysis of EAW. For the conditions, see the Materials and Methods. Peak 1 is wedelolactone, and peak 2 is luteolin.

release into the cytoplasm are essential events in the initiation of mitochondrial caspase signaling. It was found that $\mathrm{t}$-BHP treatment increased cytosolic cytochrome C, which was decreased by pretreatment with EAW or luteolin or wedelolactone (Figure 5A). The Bcl-2 family members have been found to play important roles in regulating mitochondrial-mediated apoptosis. High ratio of $\mathrm{Bcl}-2 / \mathrm{Bax}$ and $\mathrm{Bcl}-\mathrm{X}_{\mathrm{L}} / \mathrm{Bax}$ were observed to promote cell survival by preserving the integrity of the external mitochondrial membrane, which prevents the released of cytochrome $\mathrm{C}$ from the mitochondria, inducing cell death. It has been reported that overexpression of $\mathrm{Bcl}-2$ in neurons was found to protect from neuronal loss in mouse model of cerebral ischemia [24]. In addition, Bax inhibition prevented neuronal death in a mouse model of Parkinson's disease [25]. The ratio of Bcl-2/Bax and $\mathrm{Bcl}-\mathrm{X}_{\mathrm{L}} / \mathrm{Bax}$ are important in determining sensitivity to apoptotic stimuli. Therefore, we determined the effect of EAW, luteolin and wedelolactone on t-BHP-induced changes in these proteins. The treatment of PC12 cells 


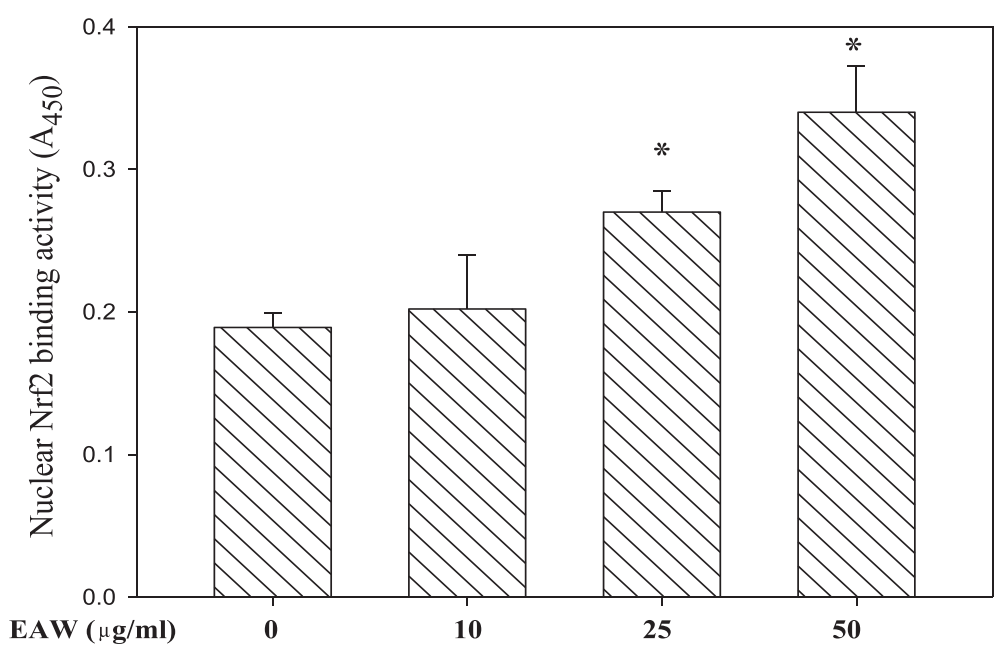

Figure 2 Effects of EAW on Nrf2 activation. After pretreatment with EAW, PC12 cells were harvested and nuclear extracts were prepared and analyzed using the TransAM Nrf2 kit, as described in the Materials and Methods. Data represent the means \pm SD $(n=3)$. ${ }^{*} P<0.05$, versus solvent control (0.1\% DMSO) treated alone.

with $100 \mu \mathrm{M}$ t-BHP for $3 \mathrm{~h}$ decreased the ratio of Bcl-2/ $\mathrm{Bax}$ and $\mathrm{Bcl}-\mathrm{X}_{\mathrm{L}} / \mathrm{Bax}$ significantly, which were reversed by the pretreatment of EAW or luteolin or wedelolactone (Figure 5B). However, PC12 cells cannot totally represent the characters of primary cultured neurons, so, the further work needs to focus directly on primary neurons.

\section{Effects of luteolin and wedelolactone on nuclear translocation of Nrf2 and $\mathrm{Y}$-GCS expression}

It has been demonstrated that some antioxidants are exerting their antioxidative effect by activating $\mathrm{Nrf} 2$, which is a master regulator of the antioxidant response [26]. Activation of Nrf2 requires its translocation into the nucleus. It showed luteolin and wedelolactone increased the nuclear translocation of Nrf2, which implicated activation of Nrf2 (Figure 6). In addition, luteolin and wedelolactone increased the protein expression of $\gamma$-glutamyl-cysteine synthetase ( $\gamma$-GCS), a product of Nrf2 target gene (Figure 6). Luteolin and wedelolactone containing phenolic structure have been reported to exhibit free radical quenching properties $[27,28]$. Therefore, luteolin as well as wedelolactone contributed to the neuroprotective potential of EAW by

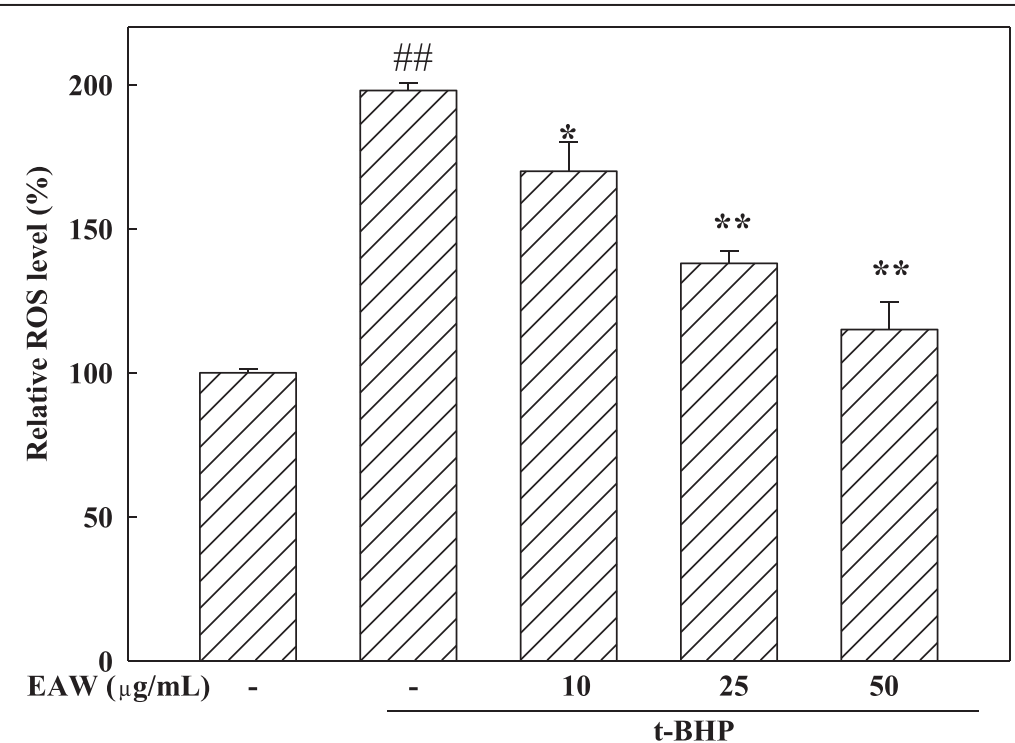

Figure 3 Effects of EAW on t-BHP-induced intracellular ROS level. After treatment, the intracellular ROS were determined using labeling with DCFH-DA as described in the text. \#\# $P<0.01$, compared to the solvent control $\left(0.1 \%\right.$ DMSO). ${ }^{*} P<0.05$ and ${ }^{* *} P<0.01$, compared to t-BHP treatment alone. 


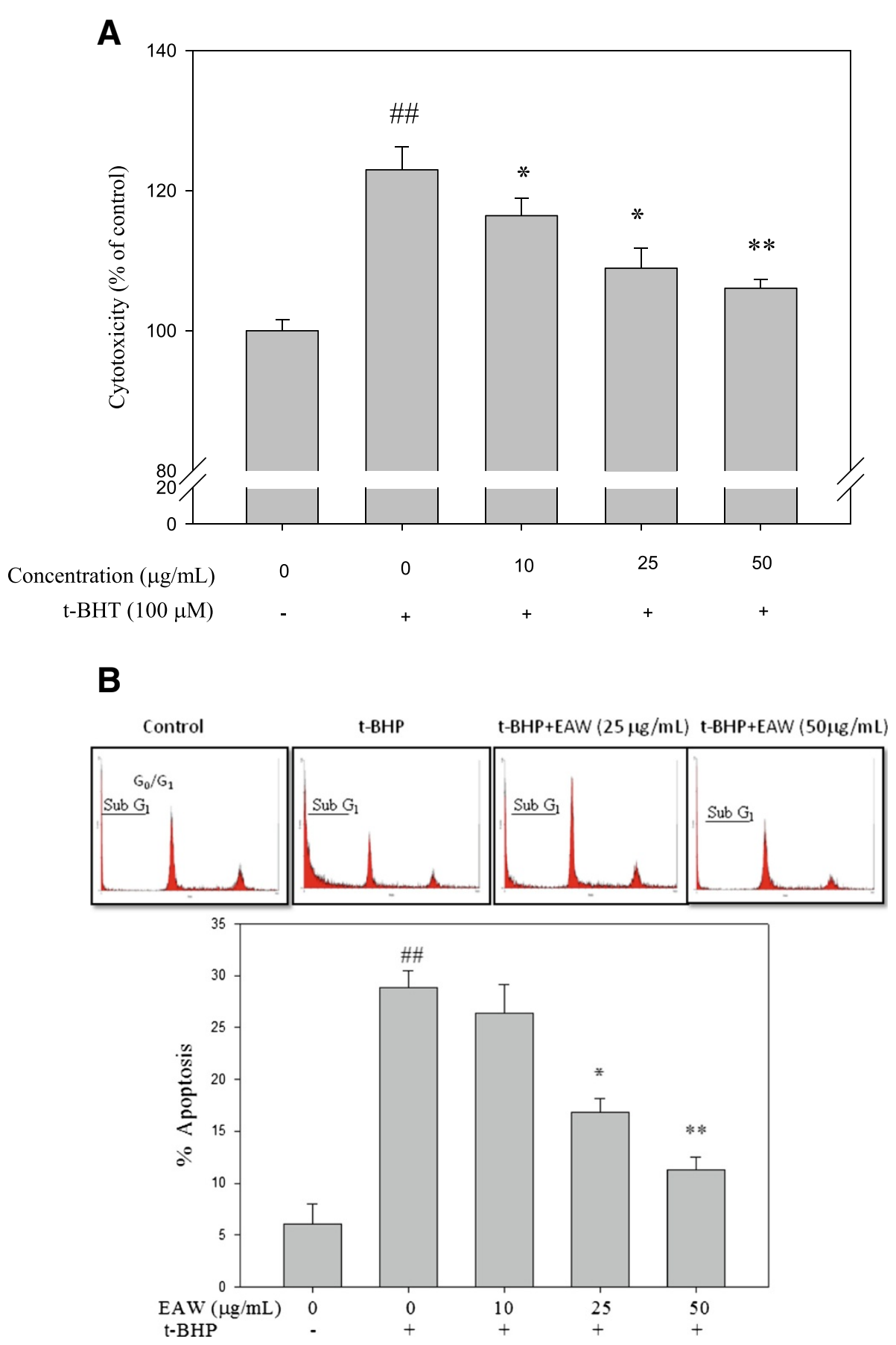

Figure 4 Effects of EAW on t-BHP-induced cytotoxicity and apoptosis in PC12 cells. PC12 cells were pretreated with EAW $(0,10,25$ and $50 \mu \mathrm{g} / \mathrm{mL}$ ) for $24 \mathrm{~h}$ and then treated with or without $100 \mu \mathrm{M}$ of t-BHP for $3 \mathrm{~h}$. (A) The cytotoxicity was determined by the LDH assay kit. (B) The DNA content was analyzed by the flow cytometry as described in the text (upper panel). The percentage of apoptotic cells (sub- $\mathrm{G}_{1}$ phase) is expressed as mean $\pm S D(n=3)$. \#\# $P<0.01$, compared to the solvent control $\left(0.1 \%\right.$ DMSO). ${ }^{*} P<0.05$ and ${ }^{* *} P<0.01$, compared to t-BHP treatment alone.

activating Nrf-2 and quenching ROS. In addition to oxidative stress, degenerative lesions are associated with inflammatory reaction [29]. Since luteolin and wedelolactone also have anti-inflammatory potential $[13,16]$, this may also contribute to the neuroprotective potential of W. chinensis.
Effect of EAW on MDA levels and neuronal cell density in the cerebral cortex of D-galactose-treated mice

Oxidative stress is proposed to be major contributor of the aging process and is linked to neurodegenerative disease such as Alzheimer's disease [30,31]. Neurodegenerative 
A

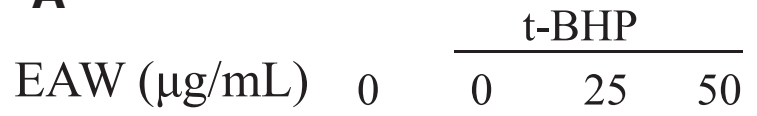

CytosolicCytochrome C

Actin
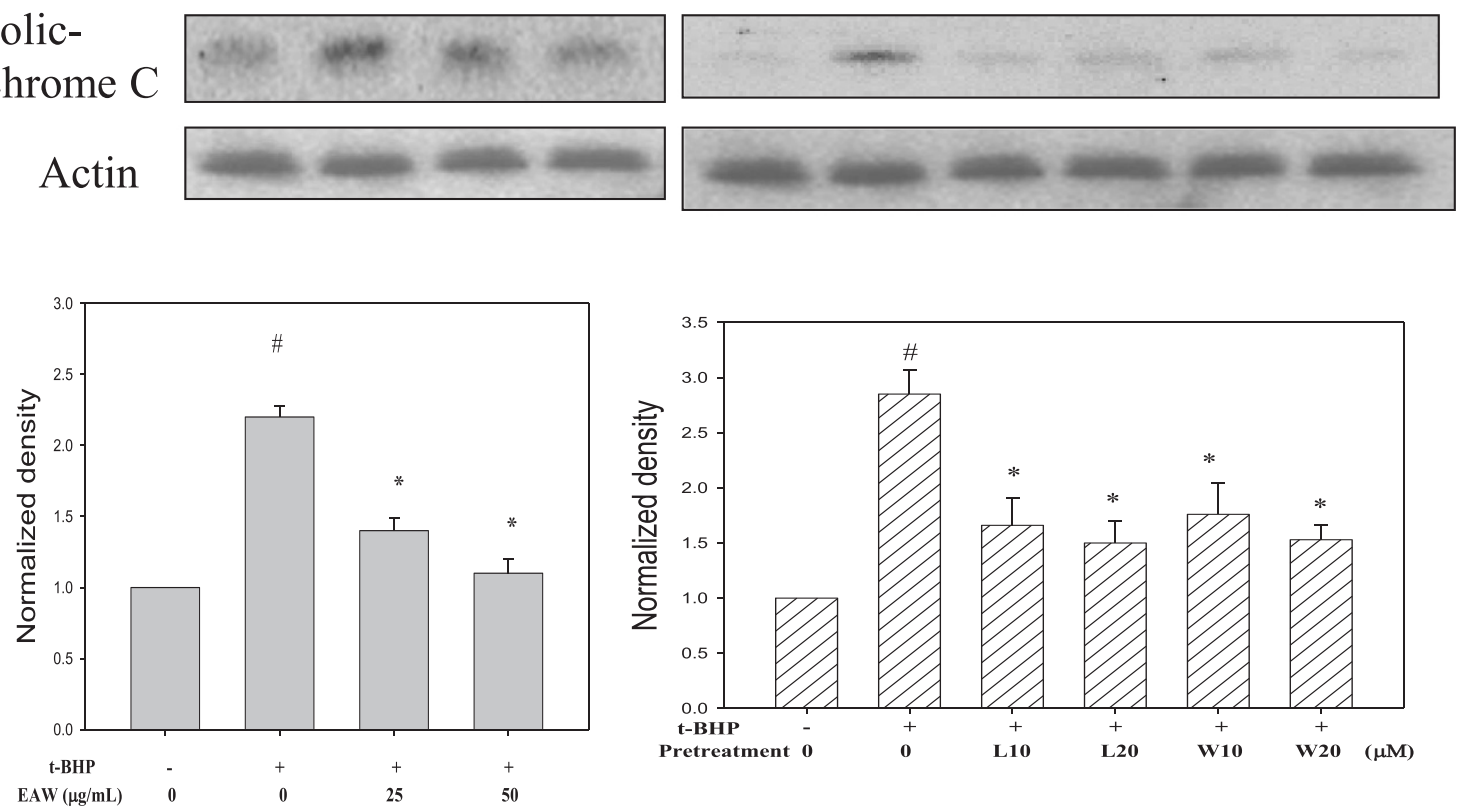

B

t-BHP
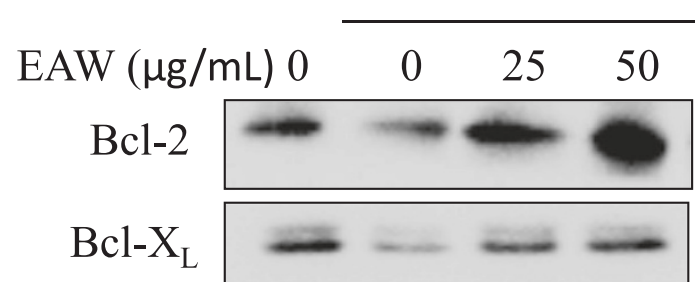

Bax

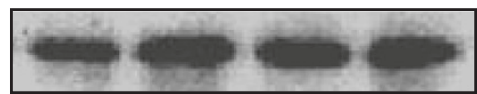

Actin
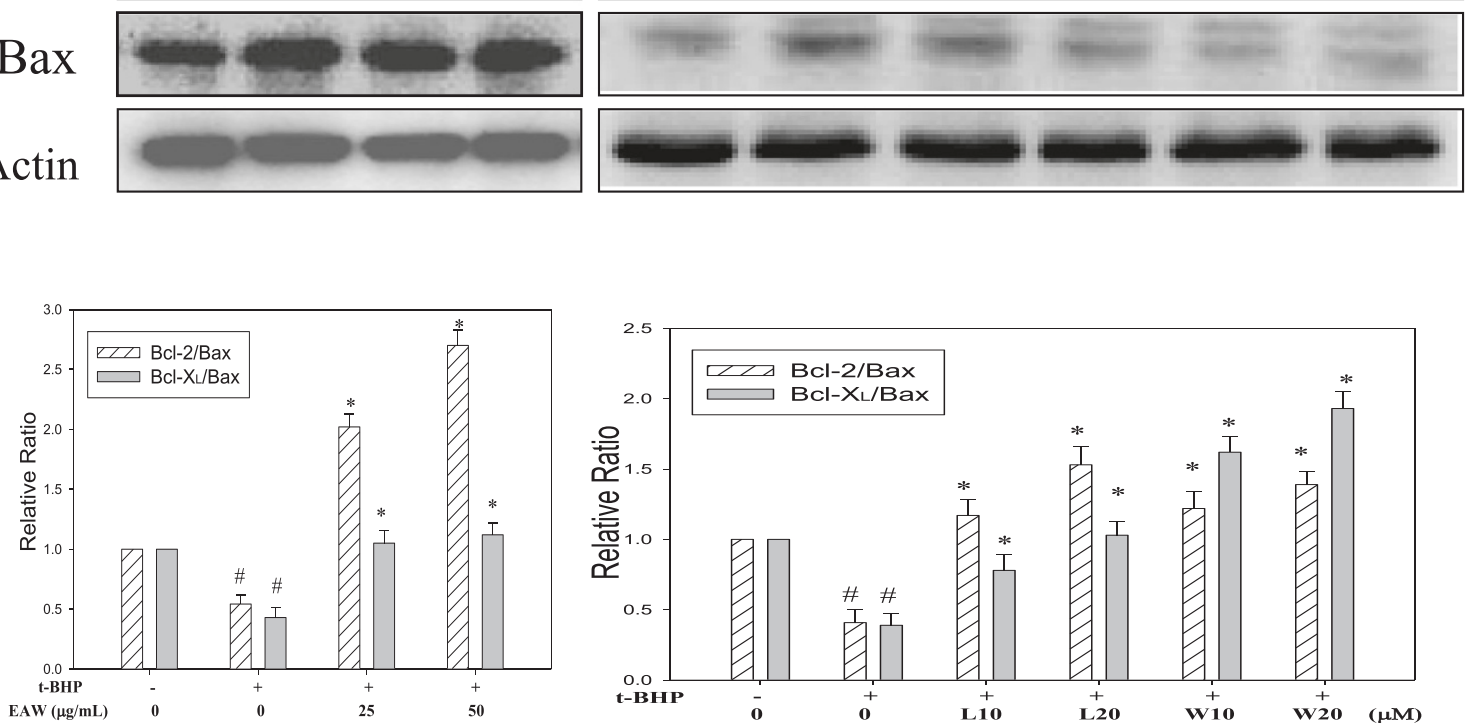

Figure $\mathbf{5}$ (See legend on next page.) 
(See figure on previous page.)

Figure 5 Effects of EAW, luteolin and wedelolactone on t-BHP-induced cytochrome $\mathrm{C}$ release and changes in Bcl-2 family proteins. PC12 cells were pretreated with EAW ( 25 and $50 \mu \mathrm{g} / \mathrm{mL})$ or luteolin $(\mathrm{L} 10,10 \mu \mathrm{M} ; \mathrm{L} 20,20 \mu \mathrm{M})$ or wedelolactone $(\mathrm{W} 10,10 \mu \mathrm{M} ; \mathrm{W} 20,20 \mu \mathrm{M})$ for $24 \mathrm{~h}$, then $100 \mu \mathrm{M}$ of t-BHP was added for $3 \mathrm{~h}$. (A) Cells were harvested after incubation, and the cytosolic protein extracts were prepared as described in the text and subjected to Western immunoblotting analysis against anti- cytochrome $\mathrm{C}$. The average densitometric value of cytochrome $C$ is shown as the mean \pm SD $(n=3)$. \# $P<0.05$, compared to the solvent control $\left(0.1 \%\right.$ DMSO). ${ }^{*} P<0.05$, compared to t-BHP treatment alone. (B) After treatment, the total cell lysates were prepared and subjected to Western immunoblotting analysis against against anti-BCl-2, $-\mathrm{BCl}-\mathrm{xL},-\mathrm{Bax}$ and anti-actin. Actin was used as the loading control. The ratio of $\mathrm{BCl}-2 / \mathrm{Bax}$ and $\mathrm{BCl}-\mathrm{xL} / \mathrm{Bax}$ are shown as the mean $\pm \mathrm{SD}$ $(\mathrm{n}=3)$. \# $P<0.05$, compared to the solvent control $(0.1 \% \mathrm{DMSO})$. ${ }^{*} P<0.05$, compared to $\mathrm{t}-\mathrm{BH}$ P treatment alone.

diseases are characterized by progressive neuronal loss that leads to functional declines. There has been a growing interest in preventing various age-related pathologic conditions in brain. One of strategies to slow or delay neuronal damage is reducing brain oxidative stress. MDA is a metabolic product of lipid peroxidation, which is generated under oxidative stress. It has been reported that high concentration of D-galactose may induce oxidative stress in brain [7]. Figure 7A shows that D-galactose treatment caused an increase in MDA levels in the cortex compared to the control group $(P<0.05)$ and that this increase was reduced by coadministration of 10 or $25 \mathrm{mg} / \mathrm{kg}$ of EAW. Since oxidative stress might induce cell apoptosis we investigated the effect of D-galactose on cell apoptosis in the cortex by TUNEL assay. This showed TUNEL-positive cells were significantly increased in the D-galactose treated group compared to the vehicle control group $(P<0.05)$, and that they were reduced by co-administration of EAW $(P<0.05$; Figure $7 \mathrm{~B}$ and $\mathrm{C})$. In addition, Figure 7D shows representative photomicrographs of hematoxylin-eosin staining in the cortex of control mice and mice treated with D-galactose with or without coadministration of EAW. Neuron cells (large nucleus and dark staining) in the sections are stained by hematoxylineosin. As shown in Figure 7E, cell counts revealed that mice treated with D-galactose for 9 weeks showed neuronal loss in the cortex compared to the vehicle control group $(P<0.05)$ and that this $\mathrm{D}$-galactose-induced neuronal cell loss was inhibited by co-administration of EAW significantly $(P<0.05)$. One might be interested in knowing the dosage of EAW when applying in the human. By using the body surface area normalization method [32], the effective dose, 10 and $25 \mathrm{mg} / \mathrm{kg}$, of EAW in preventing neuronal loss in the cortex in mice can be translated to the human equivalent dose, 0.81

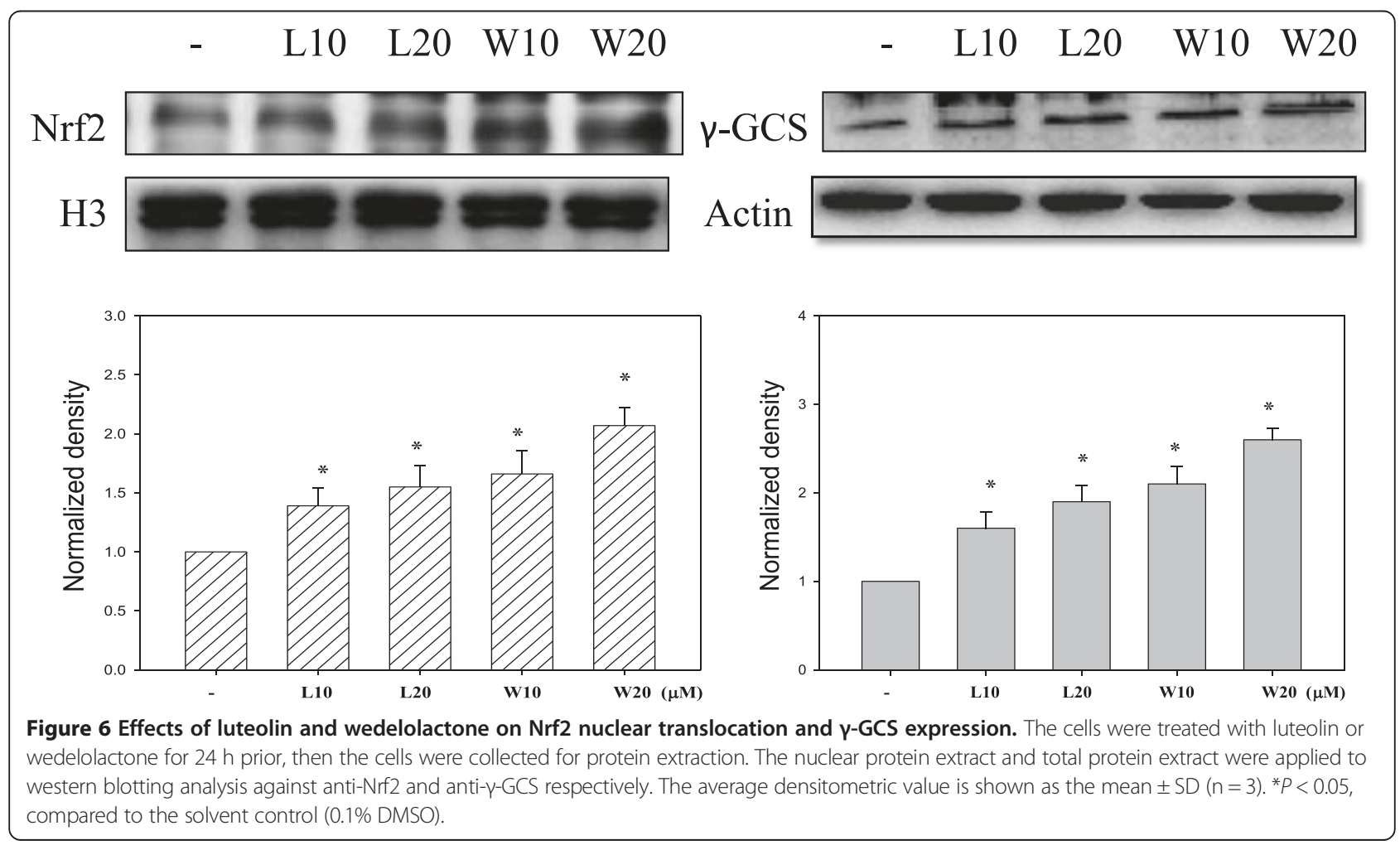



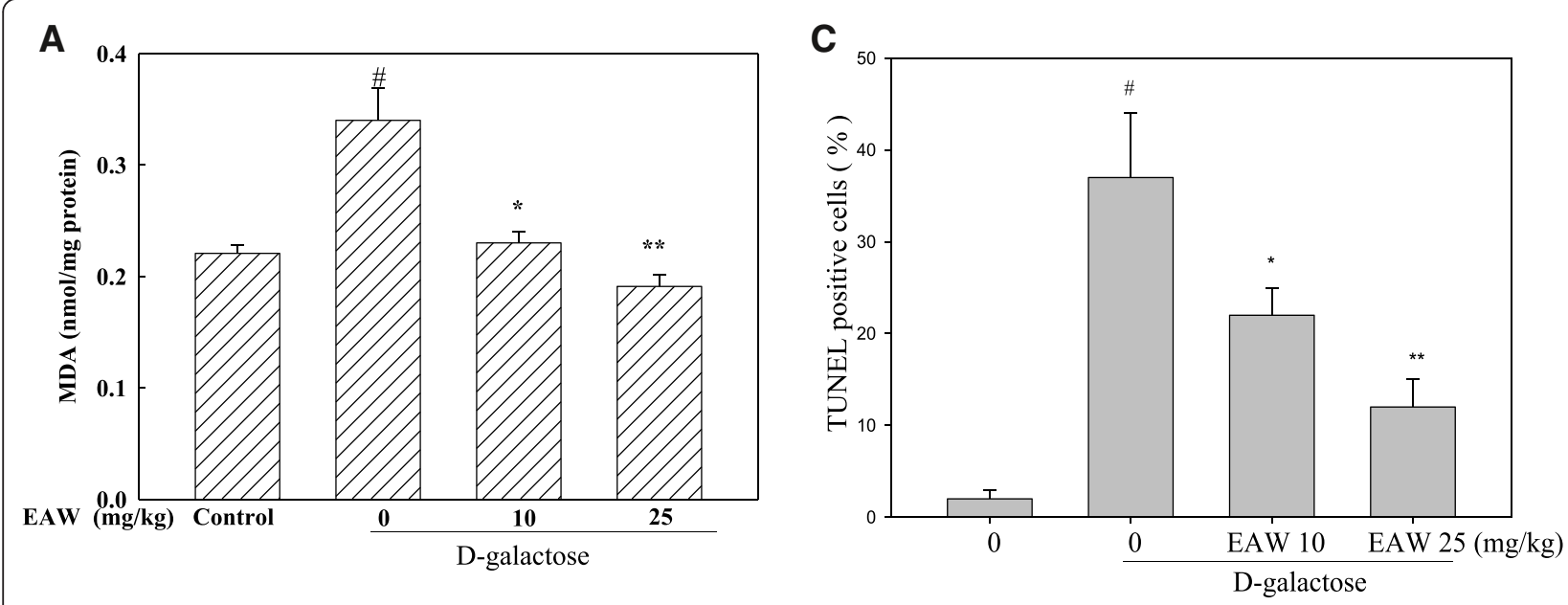

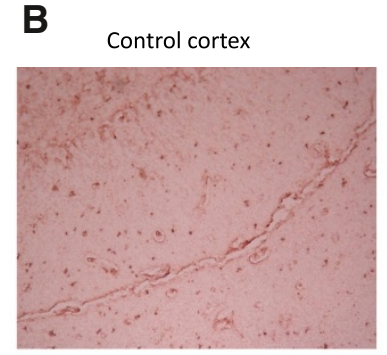

D-galactose+ EAW 10

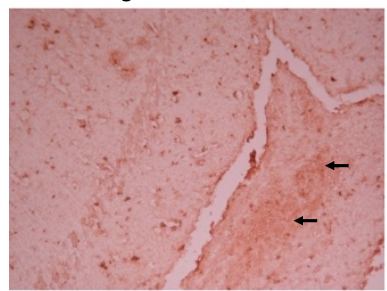

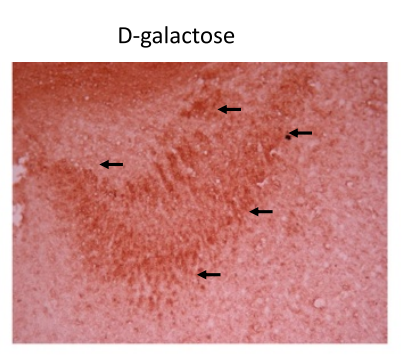

D-galactose + EAW 25

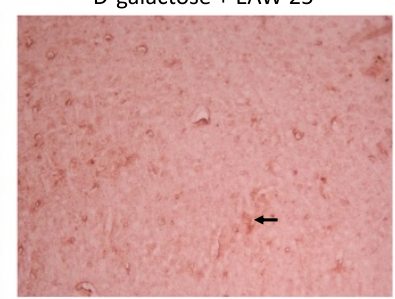

D

Control cortex

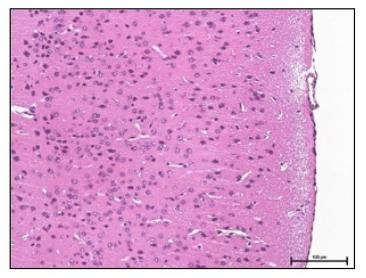

D-galactose+ EAW 10

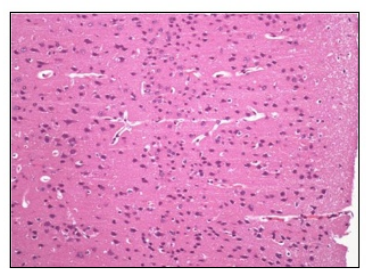

D-galactose

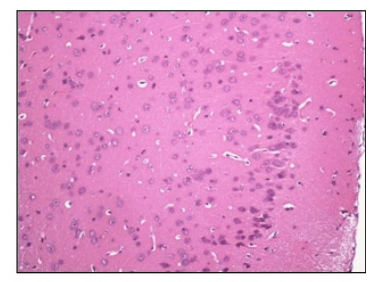

D-galactose + EAW 25

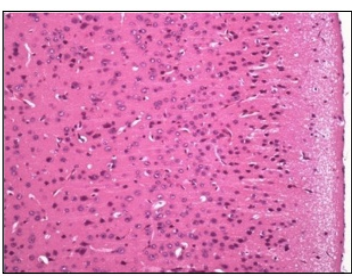

E

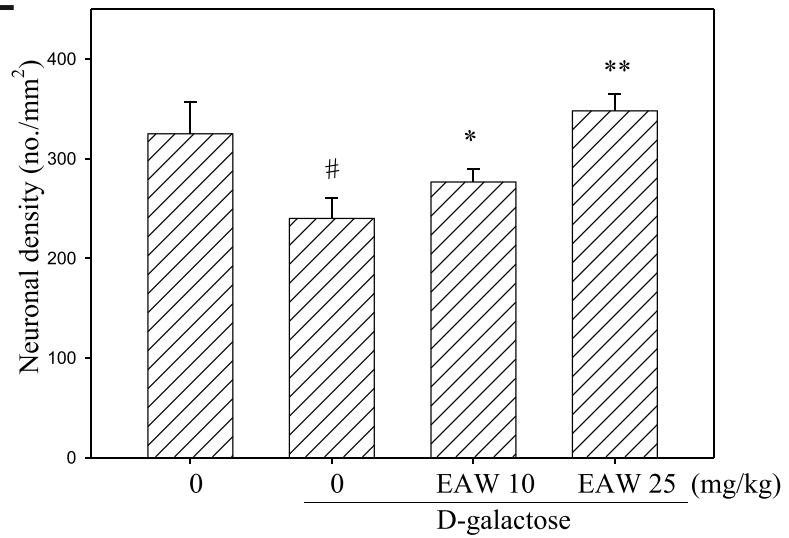

Figure 7 Effects of EAW on lipid peroxidation, TUNEL assay, and neuronal density in the cortext of D-galactose-treated mice. (A) MDA levels were analyzed as described in the text. (B) Representative of TUNEL stained brain section. Arrow indicates TUNEL positive cells. (C) TUNEL positive cells were quantified as described in the text. Data are expressed as mean \pm SD $(n=6)$. (D) Representative hematoxylin-eosin stained sections of the cortex in each group (200x). Scale bar: $100 \mu \mathrm{m}$. (E) Neuronal density calculated from the number of neurons in a $0.218 \mathrm{~mm}^{2}$ field $(400 \mathrm{x})$ and expressed as the mean \pm SD for the number of mice indicated in the text. $\# P<0.05$, compared to the control group; ${ }^{*} P<0.05$ and ${ }^{* *} P<0.01$, compared to the D-galactose-treated group. 
and $2.03 \mathrm{mg} / \mathrm{kg}$. However, further study is needed to evaluate the effective amount of $W$. chinensis when used in human for improving the health or for a therapeutic purpose.

\section{Conclusion}

EAW suppressed t-BHP-induced cytotoxicity and apoptosis by decreasing intracellular ROS through scavenging radicals and activating endogenous antioxidant capacity in PC12 cells. In vivo experiment, EAW reduced D-galactose-induced lipid peroxidation and neuron apoptosis in the cerebral cortex of mice. Further, in addition to luteolin, we found wedelolactone, induced the nuclear translocation of Nrf2 and the expression of $\gamma$-GCS. These results demonstrate that $W$. chinensis possesses neuroprotective potential by blocking oxidative stress-induced cell damage and that luteolin and wedelolactone contribute to the action. Research on other mechanisms by which EAW exerts its neuroprotective effect is currently in progress.

\section{Abbreviations}

ARE: Antioxidant response element; t-BHP: Tert-butylhydroperoxid; DPPH: 2,2diphenyl-1-picrylhydrazyl; $\gamma$-GCS: -glutamyl-cysteine synthetase; LDH: Lactate dehydrogenase; Nrf2: Nuclear factor E2-related factor 2; ROS: Reactive oxygen species; TUNEL: Terminal deoxynucleotidyl transferase dUTP nick end labeling.

\section{Competing interests}

The authors declare that they have no competing interests.

\section{Authors' contributions}

The authors participated in the data analysis and manuscript preparation. All authors approved the final manuscript.

\section{Acknowledgements}

This study was supported by grants from the Chung Shan Medical University Hospital (CSH-2012-C-018) and the Ministry of Science and Technology (NSC 99-2632-B-040-001-MY3). Densitometry was performed at the Instrument Center of Chung Shan Medical University, which is supported by the Ministry of Science and Technology, Ministry of Education and Chung Shan Medical University.

\section{Author details}

'Department of Pathology, Chung Shan Medical University Hospital, No. 110, Section 1, Chien-Kuo N. Road, Taichung 402, Taiwan. ${ }^{2}$ School of Medicine, Chung Shan Medical University, No. 110, Section 1, Chien-Kuo N. Road, Taichung Taiwan. ${ }^{3}$ School of Medical Applied Chemistry, Chung Shan Medical University, No. 110, Section 1, Chien-Kuo N. Road, Taichung 402, Taiwan. ${ }^{4}$ School of Psychology, Chung Shan Medical University, No. 110, Section 1, Chien-Kuo N. Road, Taichung 402, Taiwan. ${ }^{5}$ Department of Nursing, Chang Gung University of Science and Technology, Chia-Yi Campus No. 2, Chia-Pu Rd. West Sec. Putz, Chia-Yi 613, Taiwan. ${ }^{6}$ Department of Chemistry, National Changhua University of Education, No. 1, Jin-De Road, Changhua 500, Taiwan. ${ }^{7}$ Department of Medical Education, Chung Shan Medical University Hospital, No. 110, Section 1, Chien-Kuo N. Road, Taichung 402, Taiwan.

Received: 13 June 2014 Accepted: 10 December 2014 Published: 15 December 2014

\section{References}

1. Quintanilla RA, Orellana JA, von Bernhardi R: Understanding risk factors for Alzheimer's disease: interplay of neuroinflammation, connexin-based communication and oxidative stress. Arch Med Res 2012, 43:632-644.
2. Adams JD Jr, Klaidman LK, Huang YM, Cheng JJ, Wang ZJ, Nguyen M, Knusel B, Kuda A: The neuropathology of intracerebroventricular t-butylhydroperoxide. Mol Chem Neuropathol 1994, 22:123-142.

3. Plas EK, Aw TY: Early redox imbalance mediates hydroperoxide-induced apoptosis in mitotic competent undifferentiated PC-12 cells. Cell Death Differ 2002, 9:1007-1016.

4. lannone A, Bini A, Jin YG, Vannini V, Tomasi A: tert-Butylhydroperoxide bioactivation to methyl radical in rat liver mitochondria and submitochondrial particles. Free Radic Res Commun 1993, 19:S141-S147.

5. Guidarelli A, Clementi E, Sciorati C, Cattabeni F, Cantoni O: Calciumdependent mitochondrial formation of species mediating DNA single strand breakage in U937 cells exposed to sublethal concentrations of tert-butylhydroperoxide. J Pharmacol Exp Ther 1997, 283:66-74.

6. Hsia CH, Wang CH, Kuo YW, HO YJ, Chen HL: Fructo-oligosaccharide systemically diminished D-galactose-induced oxidative molecule damage in BALB/cJ mice. Br J Nutr 2012, 107:1787-1792.

7. Zhong SZ, Ge QH, Qu R, Li Q, Ma SP: Paeonol attenuates neurotoxicity and ameliorates cognitive impairment induced by D-galactose in ICR mice. J Neurol Sci 2009, 277:58-64.

8. Lin SC, Lin CC, Lin YH, Shyuu SJ: Hepatoprotective effects of Taiwan folk medicine: Wedelia chinensis on three hepatotoxin-induced hepatotoxicity. Am J Chin Med 1994, 22:155-168.

9. Manjamalai A, Sardar-Sathyajith-Singh R, Guruvayoorappan C, Berlin-Grace VM: Analysis of phytochemical constituents and anti-microbial activity of some medicinal plants in Tamilnadu, India. Global J Biotech Biochem 2010, 5:120-128.

10. Haldar PK, Bhattacharya S, Dewanjee S, Mazumder UK: Chemopreventive efficacy of Wedelia calendulaceae against 20-methylcholanthreneinduced carcinogenesis in mice. Environ Toxicol Phar 2011, 31:10-17.

11. Prakash T, Rao NR, Viswanatha Swamy AH: Neuropharmacological studies on Wedelia calendulacea Less stem extract. Phytomedicine 2008, 15:959-970.

12. Lin FM, Chen LR, Lin EH, Ke FC, Chen HY, Tsai MJ, Hsiao PW: Compounds from Wedelia chinensis synergistically suppress androgen activity and growth in prostate cancer cells. Carcinogenesis 2007, 28:2521-2529.

13. Seelinger G, Merfort I, Schempp CM: Anti-oxidant, anti-inflammatroy and anti-allergic activities of luteolin. Planta Med 2008, 74:1667-1677.

14. Lin CW, Wu MJ, Liu IYC, Su JD, Yen JH: Neurotrophic and cytoprotective action of luteolin in PC12 cells through ERK-dependent induction of Nrf2-driven HO-1 expression. J Agric Food Chem 2010, 58:4477-4486.

15. Lin $Y$, Shi R, Wang $X$, Shen HM: Luteolin a flavonoid with potentials for cancer prevention and therapy. Curr Cancer Drug Targets 2008, 8:634-646.

16. Kobori M, Yang Z, Gong D, Heissmeyer V, Zhu H, Jung YK, Gakidis MA, Rao A, Sekine T, Ikegami F, Yuan C, Yuan J: Wedelolactone suppresses LPS-induced caspase-11 expression by directly inhibiting the IKK complex. Cell Death Differ 2004, 11:123-130.

17. Pôças ES, Lopes DV, da Silva AJ, Pimenta PH, Leitão FB, Netto CD, Buarque $C D$, Brito FV, Costa PR, Noël F: Structure-activity relationship of wedelolactone analogues: structural requirements for inhibition of $\mathrm{Na}^{+}$, $\mathrm{K}^{+}$-ATPase and binding to the central benzodiazepine receptor. Bioorg Med Chem 2006, 14:7962-7966.

18. Kaushik-Basu N, Bopda-Waffo A, Talele TT, Basu A, Costa PR, da Silva AJ, Sarafianos SG, Noel F: Identification and characterization of coumestans as novel HCV NS5B polymerase inhibitors. Nucleic Acids Res 2008, 36:1482-1496.

19. Benes P, Knopfova L, Trcka F, Nemajerova A, Pinheiro D, Soucek K, Fojta M, Smarda J: Inhibition of topoisomerase lla: Novel function of wedelolactone. Cancer Lett 2011, 303:29-38.

20. Lee YJ, Lin WL, Chen NF, Chuang SK, Tseng TH: Demethylwedelolactone derivatives inhibit invasive growth in vitro and lung metastasis of MDA-MB231 breast cancer cells in nude mice. Eur J Med Chem 2012, 56:361-367.

21. Chang CF, Yang LY, Chang SW, Fang YT, Lee YJ: Total synthesis of demethylwedelolactone and wedelolactone by $\mathrm{Cu}$-mediated/Pd(0)-catalysis and oxidative-cyclization. Tetrahedron 2008, 64:3661-3666.

22. Yang J, Liu X, Bhalla K, Kim CN, Ibrado AM, Cai J, Peng Tl, Jones DP, Wang X: Prevention of apoptosis by $\mathrm{BCl}-2$ : release of cytochrome $\mathrm{C}$ from mitochondria blocked. Science 1997, 75:1139-1142.

23. Sinha K, Das J, Pal PB, Sil PC: Oxidative stress: the mitochondriadependent and mitochondria-independent pathways of apoptosis. Arch Toxicol 2013, 87:1157-1180.

24. Dewson G, Kluck RM: Bcl-2 family-regulated apoptosis in health and disease. Cell Health and Cytoskeleton 2010, 2:9-22.

25. Perier C, Bove J, Wu DC, Dehay B, Choi DK, Jackson-Lewis V, Rathke-Hartlieb S, Bouillet P, Strasser A, Schulz JB, Przedborski S, Vila M: Two molecular pathways 
initiated mitochondria-dependent dopaminergic neurodegeneration in experimental Parkinson's disease. Proc Natl Acad Sci U S A 2007, 104:8161-8166.

26. Scapagnini G, Sonya V, Nader AG, Calogero C, Zella D, Fabio G: Modulation of Nrf2/ARE pathway by food polyphenols: a nutritional neuroprotective strategy for cognitive and neurodegerative disorders. Mol Neurobiol 2011, 44:192-201.

27. Majewska M, Skrzycki M, Podsiad M, Czeczot H: Evaluation of antioxidant potential of flavonoids: an in vitro study. Acta Pol Pharm 2011, 68:611-615.

28. Unnikrishnan KP, Fathima A, Hashim KM, Balachandran I: Antioxidant Studies and Determination of Wedelolactone in Eclipta alba. J Plant Sci 2007, 2:459-464.

29. Jellinger KA: Basic mechanisms of neurodegeneration: a critical update. J Cell Mol Med 2010, 14:457-487.

30. Uttara B, Singh AV, Zamboni P, Mahajan RT: Oxidative stress and neurodegenerative diseases: a review of upstream and down stream antioxidant therapeutic options. Curr Neuropharmacol 2009, 7:65-74.

31. Federico A, Cardaioli E, Da Pozzo P, Formichi P, Gallus GN, Radi E: Mitochondria, oxidative stress and neurodegeneration. J Neurol Sci 2012, 322:254-262.

32. Reagan-Shaw $S$, Nihal $M$, Ahmad N: Dose translation from animal to human studies revisited. FASEB J 2007, 22:659-661.

doi:10.1186/1472-6882-14-491

Cite this article as: Lin et al:: Ethyl acetate extract of Wedelia chinensis inhibits tert-butyl hydroperoxide-induced damage in PC12 cells and D-galactose-induced neuronal cell loss in mice. BMC Complementary and Alternative Medicine 2014 14:491.

\section{Submit your next manuscript to BioMed Central and take full advantage of:}

- Convenient online submission

- Thorough peer review

- No space constraints or color figure charges

- Immediate publication on acceptance

- Inclusion in PubMed, CAS, Scopus and Google Scholar

- Research which is freely available for redistribution 